\title{
Normalization of extracellular dopamine in striatum following recovery from a partial unilateral 6-OHDA lesion of the substantia nigra: a microdialysis study in freely moving rats
}

\author{
Terry E. Robinson and Ian Q. Whishaw \\ Department of Psychology and Neuroscience Laboratory Building, The University of Michigan, Ann _, bor, MI 48109 (U.S.A.)
}

(Accepted 17 November 1987)

Key words: Dopamine: Dihydroxyphenylacetic acid; Homovanillic acid: 5-Hydroxyindoleacetic acid; Release: 6-Hydroxydopamine; Recovery of function; Amphetamine; Dialysis; Rotational behavior

\begin{abstract}
It has been hypothesized that striatal dopamine (DA) terminals undergo compensatory changes in response to partial damage of the mesostriatal DA system, which results in higher concentrations of DA in the extracellular space than would be predicted by DA concentrations in post-mortem tissue. But, this hypothesis has never been tested directly in vivo, and therefore, the present study was designed to do so. Microdialysis was used in freely moving rats to estimate the concentrations of DA, dihydroxyphenylacetic acid (DOPAC), homovanillic acid (HVA) and 5-hydroxyindoleacetic acid (5-HIAA) in striatal extracellular fluid; simultaneously from the hemisphere with a unilateral 6-hydroxydopamine (6-OHDA) lesion of the substantia nigra and from the intact hemisphere. It was found that following recovery from a 6-OHDA lesion, and during the resting state, the extracellular concentrations of DA were normal on the lesion side, even after that side was depleted of up to $99.0 \%$ of the DA measured in post-mortem tissue. Furthermore, the extracellular concentrations of DA were elevated in the intact hemisphere of animals with a $>95 \%$ DA depletion. In rats with a $<95 \%$ DA depletion amphetamine $(1.5 \mathrm{mg} / \mathrm{kg})$ caused a large increase in the extracellular concentration of DA in both the lesion and intact hemispheres (intact $>$ lesion), but in rats with a $>95 \%$ tissue DA depletion amphetamine only enhanced extracellular DA on the intact side; on the lesion side amphetamine produced a progressive decrease in extracellular DA to nondetectable levels. Animals rotated towards the lesion side. Unlike DA,the extracellular concentrations of DOPAC and HVA were greatly reduced on the lesion side, and the extent of the depletion was highly correlated with lesion size. It is concluded that following partial unilateral damage to mescstriatal DA projections there are massive changes in the remaining DA terminals that are sufficient to normalize the extracellular (and presumably synaptic) concentrations of DA. The normalization of extracellular DA concentrations seen after extensive (but incomplete) damage to the mesostriatal system must play a major role in the sparing and recovery of behavioral function that is so characteristic of this system. After extensive damage the capacity of the remaining DA neurons to respond to increased demand is limited, however, and this may explain why behavioral deficits can be reinstated by stimuli that challenge the system.
\end{abstract}

\section{INTRODUCTION}

Bilateral damage to the mesostriatal dopamine (DA) system in rats produces a syndrome that is very similar to Parkinson's disease in humans ${ }^{38.55}$, and symptoms include, bradykinesia, sensorimotor neglect, aphagia, adipsia, short-step locomotion, akathisia, excessive bracing and clinging reactions and cognitive dysfunction ${ }^{37.53 .54 .63,66,72.73,76,80}$. Unilateral damage results in pronounced behavioral asymmetries, including the hemispatial neglect and turn- ing (rotational) behavior characteristic of hemiParkinsonism ${ }^{9.35 .41 .50 .67}$. An interesting feature of 'DA depletion syndromes' is the degree to which function is spared following partial damage. Pronounced behavioral deficits typically are not manifest until striatal DA is depleted by $80-90 \%$, and even after more than $90 \%$ of striatal DA is lost there is considerable recovery of function ${ }^{7.11}$ (for reviews see refs. 62, 77). Recovery is not complete, however, because deficits can be reinstated if the system is 'challenged'; for example, by treatment with low doses of antidopami-

Correspondence: T.E. Robinson, Neuroscience Laboratory Building, The University of Michigan, 1103 E. Huron St.. Ann Arbor. MI 48109, U.S.A. 
nergic drugs or exposure to stress ${ }^{14.22,35.57,60}$.

There are a number of compensatory changes in DA activity that are known to occur after partial damage, and these are thought to contribute to sparing and recovery of function (for reviews see refs. 36, $64,77)$. Presynaptic changes, including an increase in the synthesis, metabolism, and fractional release of DA in the remaining terminals, occur after even moderate damage and probably contribute to sparing of function ${ }^{2.7 .29 .31 .58 .61 .78}$. If the depletion of striatal DA exceeds $80-90 \%$ there is also an increase in postsynaptic DA receptors (receptor supersensitivity), and in combination with presynaptic changes probably accounts in part for recovery of function $^{17.21,42.43 .65}$.

It has been hypothesized that following partial damage to the mesostriatal DA system there is an increase in DA release from the remaining terminals, and in conjunction with the loss of DA reuptake sites, this results in much higher extracellular (synaptic) concentrations of DA than would be predicted from the tissue concentrations of DA (e.g. refs. 29, 77, 78). Two kinds of evidence support this hypothesis. First, in the DA-depleted striatum of both human and nonhuman animals dihydroxyphenylacetic acid (DOPAC) and homovanillic acid (HVA) are depleted less than DA, resulting in a large increase in the ratio of DA metabolites to DA (ref. 77 and above for references). Second, studies of electrical stimulation-evoked DA release in vitro have shown that the fractional release of DA (release as a percent of the remaining DA) is elevated in striatal tissue from rats with a 6-hydroxydopamine (6-OHDA) lesion ${ }^{61}$. But these studies do not constitute a strong test of the hypothesis and are inconclusive for three reasons. (1) Measures of DA metabolism or metabolite/transmitter ratios in post-mortem tissue are not reliable indicators of DA utilization, because most metabolism takes place intraneuronally independent of DA release ${ }^{13,70,74}$. (2) It is difficult to generalize from in vitro studies to the in vivo state. For example, in vitro methods are not appropriate for studying the basal (steady state) rate of DA release, because basal DA efflux in vitro is not influenced by temperature and does not require calcium (e.g. ref. 6). Therefore, spontaneous DA efflux in vitro probably does not represent a normal physiological process akin to the basal rate of DA release associated with spontaneous unit activity in vivo. (3) It is difficult to understand how an increase in the fractional release of DA could in itself restore normal function, given that the absolute amount of released DA remains greatly depressed in animals with a 6-OHDA lesion ${ }^{33,61}$. The normalization of striatal unit activity following recovery from a 6-OHDA lesion ${ }^{45,56}$ suggests the remaining DA terminals are not only more active, relative to control terminals, but are sufficiently more active to produce a normal supply of extracellular DA (at least in the absence of postsynaptic changes or other compensatory responses).

To test the above hypothesis and resolve some of these issues intracerebral microdialysis ${ }^{68}$ was used in freely moving rats to directly measure the concentrations of DA and DA metabolites in extracellular fluid (ECF). The ECF concentrations of DA were measured simultaneously from the striatum located ipsilateral and contralateral to a unilateral 6-OHDA lesion of the substantia nigra, which allowed a withinsubject comparison of the denervated and innervated sides in vivo. Measures were made both during the resting state and after a challenge injection of amphetamine. This latter procedure was designed to test the ability of the denervated side to respond to an increased demand for DA release. At the completion of the experiment the striatum on each side was assayed to determine the tissue concentrations of DA and its metabolites. This allowed a determination of lesion size and a direct comparison of post-mortem tissue and in vivo ECF concentrations of the compounds of interest. The concentrations of 5-hydroxyindoleacetic acid (5-HIAA) in striatal tissue and dialysate were also measured to provide an index of lesion specificity.

\section{MATERIALS AND METHODS}

\section{Subjects}

The subjects were adult female Holtzman (Madison, WI) rats housed on a 14:10 h light-dark cycle (lights on $08.00 \mathrm{~h}$ ), and with free access to food and water. All testing took place during the day.

\section{Surr:al procedures}

. 1 animals received a unilateral injection of 6OHDA $\mathrm{HBr}$ into the rostral zona compacta of the substantia nigra, using standard stereotaxic proce- 
dures. Briefly, the animals were food deprived the night before surgery, and were pretreated with 25 $\mathrm{mg} / \mathrm{kg}$ of desipramine $30 \mathrm{~min}$ prior to the 6-OHDA infusion ${ }^{10}$. They were anesthetized with sodium pentobarbital, and between 3 and $8 \mu \mathrm{g}$ of 6-OHDA (dissolved in $4 \mu \mathrm{l}$ of a saline-ascorbate solution -0.1 $\mathrm{mg} / \mathrm{ml}$ ascorbate) infused through a 30 -gauge stainless-steel cannula, at a rate of $0.8 \mu \mathrm{l} / \mathrm{min}$. The cannula was left in place for $2 \mathrm{~min}$ following the injection to permit diffusion and to minimize seepage up the cannula track. Different 6-OHDA concentrations were used to insure variation in lesion size. The animals were allowed to recover for a least 1 month before the testing began, which is sufficient time for restoration of the blood-brain barrier ${ }^{15}$ and behavioral recovery of function. The animals were also screened for amphetamine-induced rotational behavior before and after the lesion, and only animals showing consistent ipsiversive rotational behavior were used in these experiments.

On the day prior to testing the animals were again anesthetized with sodium pentobarbital and a dialysis probe stereotaxically placed into the corpus of the striatum on both the left and right sides. The dialysis probes (see below) were connected to $1.0 \mathrm{ml}$ gastight Hamilton 1000 series syringes mounted on a syringe pump (Carnegie-Medicin Model 100), and a modified Ringer solution $\left(147 \mathrm{mmol} \mathrm{Na}{ }^{+}, 2.3 \mathrm{mmol}\right.$ $\mathrm{Ca}^{+}, 4 \mathrm{mmol} \mathrm{K}^{+}$and $155.6 \mathrm{mmol} \mathrm{Cl}^{-}, \mathrm{pH} 6.0$ ) pumped through the probes at a rate of $1-2 \mu \mathrm{l} / \mathrm{min}$ during the entire surgical procedure. (All solutions were filtered with $0.2-\mu \mathrm{m}$ syringe filters.) The entire assembly was held in place by enclosing it in dental cement, and it was fixed to the skull with stainlesssteel screws. The animals were then fitted with a light harness about their torso, and placed into the test arena (a $30-\mathrm{cm}$ diameter circular plexiglass chamber). The animals were left in the test chamber overnight, and the Ringer solution was continuously pumped through the probes at $0.1-0.2 \mu \mathrm{l} / \mathrm{min}$ during this time. Testing began the next day, at least $18 \mathrm{~h}$ after probe implantation (see below).

\section{Construction of the dialysis probes}

A dialysis probe ii schematically illustrated in Fig. 1. The inlet tubing, which was connected to one channel of a 3 to 4-channel liquid swivel (Harvard Bioscience), consisted of an approximately $60-\mathrm{cm}$ length of

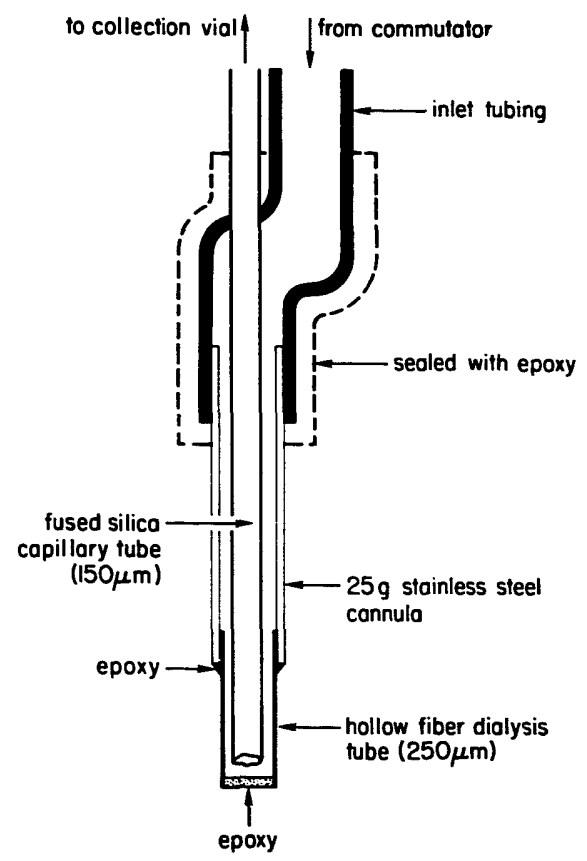

Fig. 1. Schematic illustration of a dialysis probe (see text for details).

Microline tubing (Cole-Palmer) with an inside diameter (i.d.) of $510 \mu \mathrm{m}$ and an outside diameter (o.d.) of $1.52 \mathrm{~mm}$. The other end of the Microline tubing was connected to a section of 25-gauge stainless steel tubing, which previously had been prepared as follows (see Fig. 1). An approximately $10 \mathrm{~mm}$ long piece of regenerated cellulose hollow fiber dialysis tubing was cemented into the distal end of the stainless steel tubing with 2-Ton clear epoxy (Devcon). After the junction was dry to the touch (a few hours) the dialysis fiber was trimmed to the desired length $(4 \mathrm{~mm}$ in this case), the tip sealed with epoxy, and then left to dry overnight. The dialysis fiber (Specra/Por; Spectrum Medical) had a nominal molecular weight cut-off of 6000 , an i.d. of $215 \mu \mathrm{m}$, and a wall thickness of $18 \mu \mathrm{m}$ (o.d. $=251 \mu \mathrm{m}$ ). The outlet tubing (see below) was incorporated into the probe by slipping it through the 25-gauge stainless-steel cannula and into the dialysis chamber via a small hole pierced through the inlet tubing with a 26-gauge needle. The entire upper portion of the assembly, including the junction between the inlet tubing and stainless steel cannula, and the area where the outlet tubing pierced the inlet tubing. was sealed with a coating of 2-Ton epoxy (Fig. 1). After the epoxy had cured probes were stored with their tip in a $1.5 \%$ formalin solution until needed. 
The outlet tubing consisted of a $30-\mathrm{cm}$ length of flexible fused silica capillary tubing with an o.d. of $150 \mu \mathrm{m}$ and i.d. of $75 \mu \mathrm{m}$ (Polymicro Technologies). This tubing is extremely flexible and resistent to breakage because it is coated on the outside with polyimide. The small internal volume of the fused silica tubing minimizes dead volume and greatly reduces the time it takes dialysate to reach the collection vial from the probe tip. For example, a $30-\mathrm{cm}$ length of fused silica tubing with an i.d. of $75 \mu \mathrm{m}$ has a volume of only $1.325 \mu \mathrm{l}$. Fused silica tubing is easily cut to length by maintaining tension on a section while scoring it with a diamond pencil.

These probes are inexpensive and easy to construct, and the small o.d. minimizes the considerable tissue damage produced by dialysis "loops"68. The concentric design makes it simple to implant the probe into different subcortical structures, and to sample more than one structure simultaneously.

\section{Measuren ent of probe recovery in vitro}

At least 2 days prior to implantation all probes were flushed thoroughly. The flushing procedure consisted of pumping filtered high-performance liquid chromatography (HPLC) grade water through the probes, initially at $1-2 \mu \mathrm{l} / \mathrm{min}$. For the first $20 \mathrm{~min}$ the dialysis tips were placed in a beaker containing $70 \%$ ethyl alcohol (to remove the isopropyl myristate that the fibers are originally filled with). Next, the tips were placed in HPLC water and the probes left to flush overnight at approximately $0.5 \mu \mathrm{l} / \mathrm{min}$. It was found that thoroughly flushing the probes prior to use increased recovery rates and reduced variability. Either the day before implantation, or the same day as surgery, the water was removed from the probes by gentle suction with the attached syringe and they were filled with freshly prepared filtered Ringer solution. The Ringer solution was pumped through the probes at $1.5 \mu \mathrm{l} / \mathrm{min}$, with the dialysis tips in a beaker containing Ringer solution. After at least $30 \mathrm{~min}$ the beaker of Ringer was replaced with a beaker containing Ringer plus $200 \mathrm{pg} / \mu \mathrm{l}$ of DA, DOPAC, HVA and 5-HIAA (plus $1 \mathrm{mg}$ ascorbate $/ 100 \mathrm{ml}$ ). After waiting 10 min two 10- to 15 -min dialysis samples were collected and the dialysate assayed by HPLC with electrochemical detection (HPLC-EC). Recovery was calculated for each probe as described previously ${ }^{68}$, and the average of two samples used. For the present experiment recovery was determined at room temperature, but probe recovery is now routinely tested at $37^{\circ} \mathrm{C}$, which provides a more accurate assessment of recovery in vivo ${ }^{69}$. In separate experiments probe recovery was tested as a function of perfusion rate.

\section{In vivo microdialysis and behavioral test procedures}

To prevent the head assembly from absorbing the torque created when the animal moved each animal's harness was attached to a liquid swivel by a length of piano wire (or a coiled steel tether). The inlet and outlet tubing was attached to the tether and dialysate was collected in minivials that were also attached to the tether, about $30 \mathrm{~cm}$ above the animal. Thus, collection vials could be quickly exchanged without touching the animal or impeciing its movement in any way.

On the morning of a test day the pump speed was set at $1.5 \mu \mathrm{l} / \mathrm{min}$. and after at least $30 \mathrm{~min}$, dialysate samples were collected in tubes containing $10 \mu \mathrm{l}$ of a $0.05 \mathrm{~N}$ perchloric acid solution, which also contained $2.5 \mu \mathrm{l}$ of $1 \mathrm{M}$ sodium bisulfite and $250 \mu \mathrm{l}$ of $0.2 \mathrm{M}$ EDTA (per $25 \mathrm{ml}$ of $\mathrm{HClO}_{4}$ ). At least 3 baseline samples were collected over 20 to 30 -min intervals, and for this experiment 4-6 baseline samples were frequently taken. Samples were stored on ice for short periods, but all were assayed by the end of the test day. After at least 3 baseline samples were collected and assayed the animals received a subcutaneous injection of $1.5 \mathrm{mg} / \mathrm{kg}$ of D-amphetamine sulfate (weight of the salt) into the flank. After this, 4 more samples were collected over 30-min intervals.

Behavior was videotaped and subsequently analyzed by viewing the videotapes at 2-8 times normal speed. Every $360^{\circ}$ turn to the left or right was recorded over 15 -min intervals. Net rotations were calculated by subtracting the total number of turns in the non-preferred direction from those in the preferred direction.

\section{Assay of striatal tissue}

At the end of the experiment the tubing leading to the dialysis probe was severed at the level of the dental cement 'cap', the open ends were sealed with epo$x y$, and the animal was returned to it's home cage for at least 4 days. Each animal was then killed by decapitation, its brain rapidly removed and placed in icecold saline. After the brain cooled (30-45 s) it was 
placed in a chilled cutting block and brain slices obtained as described by Heffner et al. ${ }^{27}$. The slices were immediately examined and the approximate location of the 'track' formed by the dialysis probe was noted. The left and right striatum were then dissected out with a 3.0-mm diameter micropunch, weighed, and placed in individual tubes containing $0.05 \mathrm{~N}$ perchloric acid and dihydroxybenzylamine (internal standard). The samples were homogenized and centrifuged at $5000 \mathrm{~g}$ for $45 \mathrm{~min}$ at $2-4{ }^{\circ} \mathrm{C}$. The supernatant was filtered through $0.45-\mu \mathrm{m}$ syringe filters (Gelman Sciences; Arco LC3A) and stored frozen at $-20{ }^{\circ} \mathrm{C}$ for no more than two weeks before being assayed by HPLC-EC, using procedures similar to those described previously ${ }^{52}$.

\section{Assay of dialysate}

Dialysis samples were also assayed by HPLC-EC, but under different conditions than for tissue, and on a system used exclusively for diaiysate. No more than $50 \mu \mathrm{l}$ of dialysate was injected directly on the column, with no pretreatment, via a Rheodyne injection valve with a $100-\mu l$ sample loop. The column was either a 10-cm-long Bioanalytical Systems Phase-2 ODS-reverse phase column (RP-18; 3- $\mu$ m particles), or a Brownlee 10-cm-long OD-Microbore reverse phase column (RP-18; 5- $\mu \mathrm{m}$ particles; $2.1 \mathrm{~mm}$ i.d.). The mobile phase contained $0.05 \mathrm{M} \mathrm{Na} \mathrm{PO}_{4}, 0.03 \mathrm{M}$ citric acid, $0.1 \mathrm{mM}$ EDTA, $0.01 \% \mathrm{Na}$ azide, 6-9\% $\mathrm{CH}_{3} \mathrm{CN}$ and 2.6-3.3 mM sodium octyl sulfate, at an apparent $\mathrm{pH}$ of 3.35. The mobile phase was filtered and degassed with vacuum, and then pumped through an Erma degasser (Model ERC 3511) before reaching the column. Under these conditions DA eluted relatively late, following DOPAC, 5-HIAA and HVA, and was usually separated from HVA by 2-3 min. The total run time was 8-10 min. Some sensitivity was lost because DA eluted so late, but because DA metabolite concentrations in dialysate are typically about 100 times greater than DA, it was found that the advantages of keeping DA well away from the metabolites outweighed the disadvantages.

A single glassy carbon working electrode and a $\mathrm{Ag} / \mathrm{AgCl}$ reference electrode fitted directly into the thin-layer region formed by a BAS 'green' gasket $(50.8 \mu \mathrm{m})$ were used with a LC-4A Bioanalytical Systems amperometric controller. The sensitivity was set at 1-2 $\mathrm{nA} / \mathrm{V}$, with an electrode potential of $+0.76 \mathrm{~V}$.
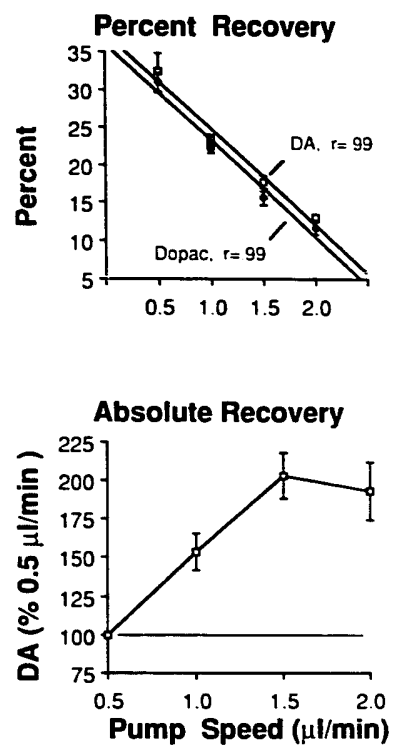

Fig. 2. Top: percent of DA and DOPAC in the external solution recovered in dialysate in vitro (relative recovery), as a function of perfusion rate (4-mm-long probes). The symbols represent the mean \pm S.E.M. for 6 probes, and if S.E.M. bars are not shown it is because they are smaller than the symbol. Percent recovery varied linearly over this range of pump speeds, with $r=-0.99$ for bott: DA and DOPAC. Similar values were obtained for 5-HIAA and HVA (not shown). Bottom: the concentration of a DA standard solution recovered in dialysate in vitro per unit time (absolute recovery) as a function of perfusion rate, and expressed as a percent of the value obtained at $0.5 \mu \mathrm{l} / \mathrm{min}$. Note that absolute recovery peaked at 1.5 $\mu \mathrm{l} / \mathrm{min}$.

Signals were recorded with a Hewlett Packard $3390 \mathrm{~A}$ recording integrator, and the amount of each compound determined by comparison with the peak height of standards run with each assay $(200 \mathrm{pg} / \mu \mathrm{l}$ of DOPAC, HVA and 5 -HIAA; $20 \mathrm{pg} / \mu \mathrm{l}$ of DA).

\section{Data analysis}

Dialysate values are reported as pg of the compound per $\mu$ l of dialysate, after correcting for probe recovery. Baseline values represent the average of at least 3 samples obtained over 2-3 h prior to amphetamine administration. At $1.5 \mu \mathrm{l} / \mathrm{min}$ and room temperature the average ( \pm S.E.M.) relative recovery rates for the probes used in this experiment were: DA $-18.01 \pm 0.95 \%$; DOPAC $-16.64 \pm 0.90 \%$ HVA $-14.74 \pm 0.79 \%$; and 5-HIAA $-15.88 \pm$ $1.03 \%(n=20)$. Recovery varies with perfusion rate and for the probes described here (4 $\mathrm{mm}$ long) relative recovery ranged from $32 \%$ at $0.5 \mu \mathrm{l} / \mathrm{min}$ to $12 \%$ at $2.0 \mu \mathrm{l} / \mathrm{min}$ (see Fig. 2). The absolute recovery rate 
was maximal at $1.5 \mu \mathrm{l} / \mathrm{min}$ (Fig. 2), which is why that pump speed was used in the present experiments. The values reported here represent, therefore, an estimate of the concentrations of the compounds of interest in striatal ECF (see ref. 69 for a discussion of problems in estimating the actual ECF concentrations of neurochemicals with microdialysis).

Analyses of variance, $t$-tests, and correlation coefficients were performed using a Macintosh Plus Computer with Statview $512^{+}$software (BrainPower).

\section{RESULTS}

\section{Post-mortem tissue measures and probe placement}

Of the 10 rats in this study, 8 had a $>66 \%$ striatal tissue DA depletion (lesion side relative to the intact side), one had a $38 \%$ depletion, and in one there was only a $1 \%$ depletion. Table I shows the average striatal tissue concentrations of DA, DOPAC, HVA and 5-HIAA on the lesion and intact sides in the 8 animals with a substantial tissue DA depietion (arbitrarily defined as $>66 \%$ ). The striatal tissue concentrations of DA, DOPAC, and HVA were greatly reduced on the lesion side, relative to the intact side, but the lesion had no effect on 5-HIAA (Table I). One animal had an abnormally high 5-HIAA value on the lesion side, which accounts for the high mean and S.E.M. values shown in Table I. DA was depleted to a greater extent than were DA metabolites, and this is indicated by significantly higher DOPAC/DA and HVA/DA ratios on the lesion side than on the intact side (Fig. 3).

The dialysis probes were all located within the corpus of neostriatum centered around the coronal plane located $0.8 \mathrm{~mm}$ anterior to bregma in the Paxinos and Watson atlas ${ }^{47}$. Individual probes varied by $\pm 0.5 \mathrm{~mm}$ along the anterior-posterior axis. The dialysis tips ranged from 2 to $3 \mathrm{~mm}$ lateral to the midline in the medial-lateral plane, and extended through the entire dorsal-ventral extent of the striatum (i.e. for about $4 \mathrm{~mm}$ ventral to the corpus callosum). Fig. 4 illustrates the approximate location of a dialysis probe drawn to scale on a coronal section through the striatum.

Basal (resting) extracellular fluid (ECF) concentrations of DA, DOPAC, HVA and 5-HIAA

All animals were habituated to the test chamber overnight and were tested during the next lights-on period, and therefore they were relatively inactive during baseline sample collection, sometimes falling asleep. They occasionally engaged in short bouts of exploratory activity or grooming, but for most of each sample period they sat still except for periodic head movements. They did not show spontaneous rotational behavior.

The 6-OHDA lesion did not have the same effect on ECF concentrations of DA (estimated from the concentrations in dialysate) as on tissue concentrations of DA (Table I). There was a $91.6 \%$ depletion in the tissue concentrations of DA on the lesion side but only a $34.8 \%$ reduction in the ECF concentrations of DA (ECF DA), which is significantly less than the percent depletion in tissue $(t=5.8, P<$ 0.001 ). In contrast to DA, the ECF concentrations of DOPAC and HVA were severely reduced on the lesion side, and the reduction was comparable to that in tissue (Table I). The lesion had no effect on the ECF concentrations of 5-HIAA (Table I).

Table I suggests that the ECF concentrations of DA are not highly predictive of tissue DA concentrations, even when tissue concentrations vary greatly because of damage to one side. This interpretation is supported by the correlation matrix shown in Table II. It can be seen from Table II that ECF DA was not significantly correlated with any other measure. On

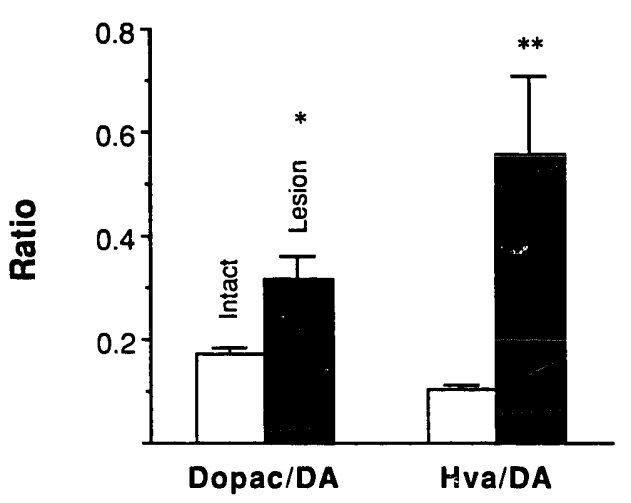

Fig. 3. The mean ( \pm S.E.M.) ratio of DOPAC/DA and HVA/ DA for striatal tissue obtained from the intact and 6-OHDA lesion side of the 8 animals sustaining a $>66 \%$ DA depletion (Table I). The DA metabolite/transmitter ratios were significantly elevated on the lesion side, relative to the intact side, because DA was depleted to a greater extent than were DA metabolites. ${ }^{*} P=0.012 ;{ }^{* *} P=0.005$ (paired $t$-tests). 
TABLE I

Mean ( \pm S.E.M.) dopamine and monoamine metabolite concentrations in striatal tissue and dialysate (extracellular fluid)

$\%$, percent depletion (lesion relative to intact).

\begin{tabular}{|c|c|c|c|c|c|}
\hline \multirow[t]{2}{*}{ Compound } & \multirow[t]{2}{*}{ Side } & \multicolumn{2}{|l|}{ Tissue } & \multicolumn{2}{|l|}{ Dialysate } \\
\hline & & $n g / m g$ & $\%$ & $p g / \mu l$ & $\%$ \\
\hline \multirow[t]{2}{*}{ DA } & intact & $12.97 \pm 0.55$ & & $10.59 \pm 2.46$ & \\
\hline & lesion & $1.11 \pm 0.56^{* *}$ & 91.6 & $6.90 \pm 1.94^{*}$ & $34.8^{* * *}$ \\
\hline \multirow[t]{2}{*}{ DOPAC } & intact & $2.20 \pm 0.17$ & & $1060 \pm 238$ & \\
\hline & lesion & $0.28 \pm 0.15^{* *}$ & 87.3 & $188 \pm 880^{* *}$ & 82.3 \\
\hline \multirow[t]{2}{*}{ HVA } & intact & $1.36 \pm 0.09$ & & $1007 \pm 207$ & \\
\hline & lesion & $0.22 \pm 0.07^{* *}$ & 83.8 & $192 \pm 720^{* *}$ & 80.9 \\
\hline \multirow[t]{2}{*}{ 5-HIAA } & intact & $1.12 \pm 0.22$ & & $429 \pm 751$ & \\
\hline & Iesion & $2.09 \pm 1.02$ & -87 & $478 \pm 102$ & -11 \\
\hline
\end{tabular}

${ }^{*}$ Differs from intact, $P<0.02{ }^{* *} P<0.005$ (paired $t$-tests); ${ }^{* * *}$ Differs from $\%$ depletion in tissue, $P<0.001$ (unpaired $t$-test).

TABLE II

Correlation matrix for DA and DA metabolites in striatal tissue and dialysate

T, tissue; D, dialysate; DPC, dopac.

\begin{tabular}{llllll}
\hline & $D A-T$ & $D P C-T$ & $H V A-T$ & $D A-D$ & $D P C-D$ \\
\hline DPC-T & $0.949^{*}$ & - & - & - & - \\
HVA-T & $0.958^{*}$ & $0.925^{*}$ & - & - & - \\
DA-D & 0.315 & 0.295 & 0.362 & - & - \\
DPC-D & $0.737^{*}$ & $0.642^{*}$ & $0.699^{*}$ & 0.401 & - \\
HVA-D & $0.738^{*}$ & $0.680^{*}$ & $0.652^{*}$ & 0.341 & $0.889^{*}$ \\
\hline
\end{tabular}

${ }^{*} \mathrm{df}=15, P<0.01$.

the other hand, the ECF concentrations of DOPAC and HVA were highly predictive of each other, and of the tissue concentrations of DA, DOPAC and HVA.

Analysis of individual animals and $<95 \%$ and $>95 \%$ DA-depleted subgroups

Further analyses were conducted to determine if the high ECF concentrations of DA seen in Table I were primarily due to animals with a moderate lesion, and whether the effect of a large lesion (>95\% DA depletion) was masked by averaging values from animals that varied so much in lesion size.

Fig. 5 shows the tissue and ECF concentrations of DA, DOPAC, HVA and 5-HIAA in each of the 10 rats studied, with the concentration on the lesion side expressed as a percent of the intact side. Note that a $\log _{10}$ scale was used to resolve differences between animals with large lesions. There are 3 points to be made from examination of Fig. 5. (1) The ECF concentrations of DA on the lesion side were very high, relative to tissue DA concentrations, regardless of lesion size (Fig. 5A). (2) The ECF concentrations of DOPAC and HVA on the lesion side dccreased proportionally with decreases in tissue concentrations, and as a function of increasing lesion size (Fig. 5B, C). (3) Neither the ECF nor tissue concentrations of 5-HIAA were reduced on the lesion side (Fig. 5D).

In addition to inspection of individual animals statistical comparisons were made between animals with a $<95 \%$ tissue DA depletion $(n=4$, mean depletion $=84.5 \%$; range $=66-94.7 \%)$ and those with a $>95 \%$ tissue DA depletion $(n=4$; mean $=99.0 \%$; range $=98.7-99.3 \%$ ). These groups will be referred to as the $<95 \%$ DA depletion and $>95 \%$ DA depletion oroups, respectively. Rat number 1 and number 5 (Fig. 5) were excluded from this analysis, except where noted, because they did not have a substantial lesion, and to reduce variability in the $<95 \%$ depleted group.

Fig. 6 shows the mean (+ S.E.M.) tissue and ECF concentrations of DA, DOPAC, and HVA on the 
intact and lesion sides of the $<95 \%$ DA depletion and $>95 \%$ DA depletion groups. The $1+\log _{10}$ transformed data were subjected to 2-way analyses of variance, with the two factors being side (intact vs lesion) and size of lesion (<95\% vs $>95 \%$ ). For the tissue concentrations of DA, DOPAC and HVA (Fig. 6A,C,E) and for the ECF concentrations of DOPAC and HVA (Fig. 5D,F) the results were identical. There was a statistically significant effect of side (i.e. concentrations were lower on the lesion side) and a significant interaction, indicating that the lesion side (but not the intact side) was depleted more in the $>95 \%$ group than in the $<95 \%$ group.

In contrast, the analysis of variance did not result in a significant eifect of lesion side or size on the ECF concentrations of DA (Fig. 6B; $F_{\text {side }}=1.8, P=0.20$; $F_{\text {size }}=2.9, P=0.112 ; F_{\text {side } \times \text { size }}=0.75, P=0.40$ ). What is especially notable in Fig. 6B, however, is that ECF DA on the intact side of $>95 \%$ depleted animals is greater than on the lesion side (paired $t$-test, $t$ $=5.48, P=0.012$ ). Furthermore, if rat numbers 1 and 5 are included (to increase the $n$ for the intact

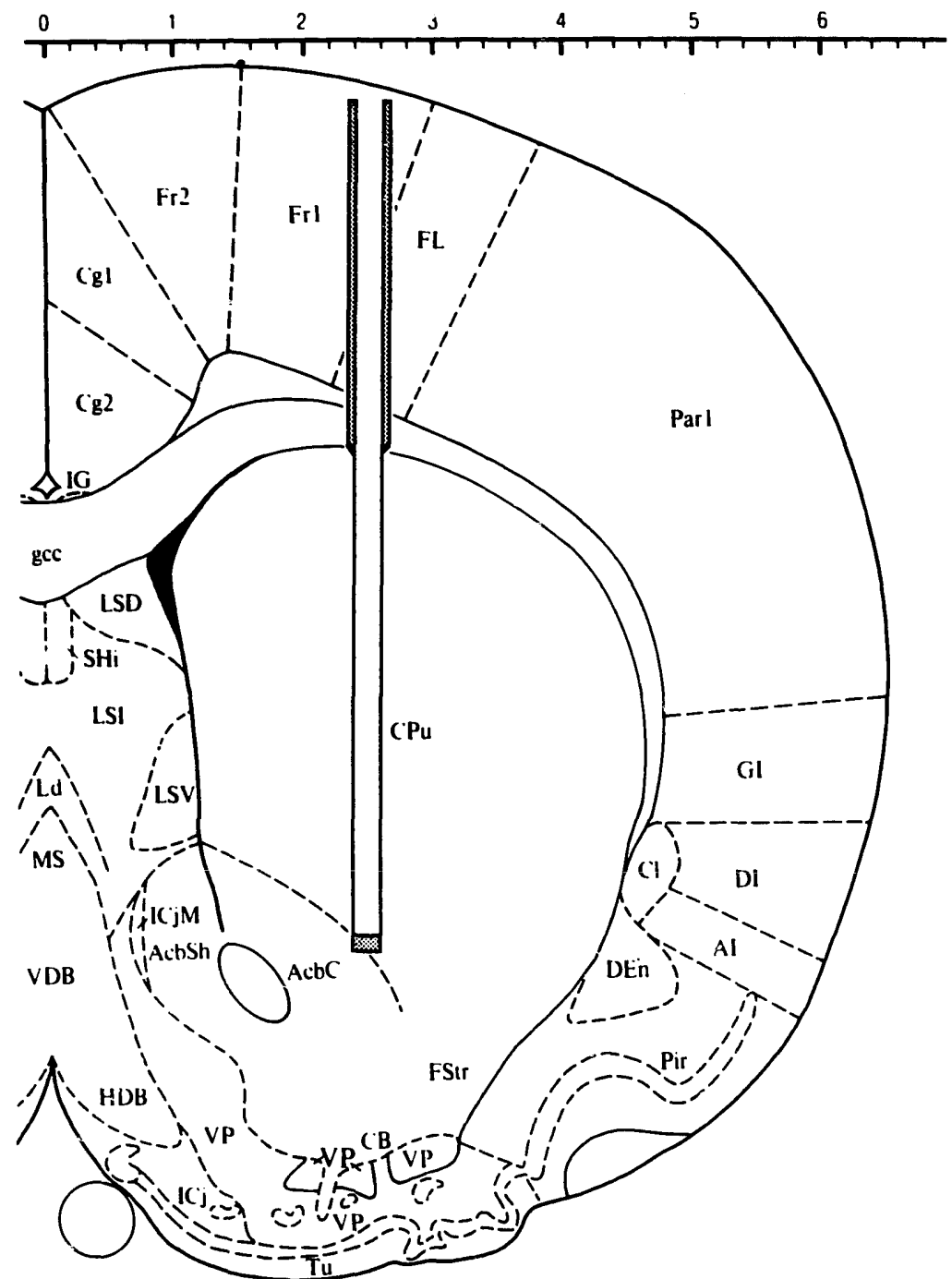

Fig. 4. The location of a dialysis probe drawn to scale on a coronal section of the rat brain from Paxinos and Watson ${ }^{47}$. The portion below the corpus callosum represents the hollow fiber dialysis membrane, and diffusion from the extracellular space can take place throughout the length of this fiber. 
side comparisons only) ECF DA on the intact side of $>95 \%$ depleted animals was significantly higher than on the intact side of $<95 \%$ depleted animals $(t=$ 2.46, $P=0.039$ ).

\section{Baseline measures in rats with no lesion}

The concentration of DA in striatal dialysate was also measured in a series of 10 neurologically intact (i.e. no lesion) Holtzman rats that were in a different experiment, but otherwise tested under exactly the same conditions as described here. The average ( \pm S.E.M.) ECF concentrations of striatal DA during baseline in these animals was $6.64 \pm 0.54 \mathrm{pg} / \mu \mathrm{l}$ (see Fig. 6B). This is significantly lower than on the intact side of rats with a $>95 \%$ depletion (mean $=14.63 \pm$ $3.3 \mathrm{pg} / \mu \mathrm{l} ; t=3.73, P=0.003)$, but no different than on the lesion side of $>95 \%$ depleted rats (or either side of $<95 \%$ depleted rats). These observations suggest that the apparent reduction in the ECF concentrations of DA on the lesion side, when concentrations on the lesion side were expressed as a percent of the intact side (Table I and Fig. 5), was not due to a reduction on the lesion side but actually to an increase on the intact side!

\section{Fractional $D A$ efflux in dialysate}

To estimate what proportion of the available DA is represented by the ECF concentrations of DA shown
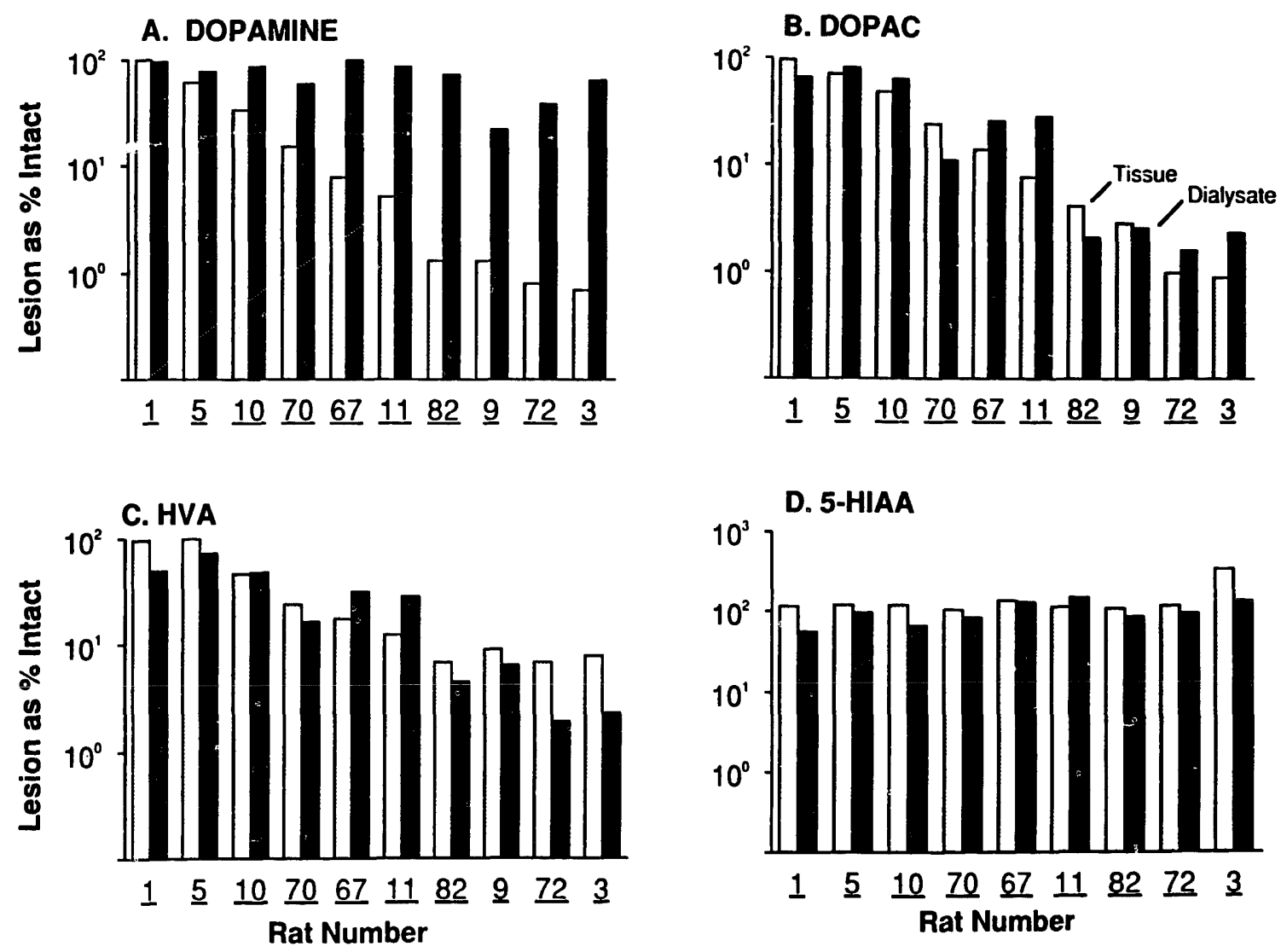

Fig. 5. The concentration of DA (A), DOPAC (B), HVA (C) and 5-HIAA (D) in striatal tissue (shaded bars) and striatal dialysate (solid bars) from 10 individual rats, with the concentration on the side with a 6-OHDA lesion expressed as a percent of the intact side. Note that the vertical axis is a $\log _{10}$ scale, and therefore, the horizontal axis $\left(10^{-1}\right)$ represents a $99.9 \%$ depletion, $10^{\circ}$ a $99 \%$ depletion. $10^{1}$ a $90 \%$ depletion, and $10^{2}$ no depletion (i.e. the lesion side is $100 \%$ of the intact side). The individual animals were arranged in order of increasing lesion size (left to right) as indicated by DA concentrations in striatal tissue (panel A), and this same order was repeated in panels B-D. The 5-HIAA values were lost for one animal, and therefore, only 9 are shown in panel D. Note that only for $\mathrm{DA}$ is there a dissociation between tissue and dialysate values as a function of increasing lesion size. 
in Fig. $6 B$, the percent of total DA in the extracellular space was calculated by dividing ECF DA concentrations $(\mathrm{pg} / \mu \mathrm{l})$ by total tissue DA concentrations (pg/mg) and multiplying by 100 . In animals with a $>95 \%$ DA depletion ECF DA on the intact side represents $0.118 \pm 0.025 \%$ of the total DA in tissue, but on the lesion side accounts for $6.33 \pm 2.19 \%$ of total DA (range $=2.4-10.6 \%$ ); a 53-fold difference. On the intact side of $<95 \%$ depleted animals $(n=6)$ ECF DA only accounts for $0.049 \pm 0.013 \%$ of total DA, which is significantly less than the comparable figure for $>95 \%$ depleted rats $(t=2.77, P=0.024)$. To further appreciate the magnitude of the increase in the proportion of DA located extracellularly on the lesion side of $>95 \%$ depleted rats, consider that following $1.5 \mathrm{mg} / \mathrm{kg}$ of amphetamine the average peak concentration of ECF DA on the intact side was only $0.432 \pm 0.124 \%$ of total DA, which is over 14 times less than basal levels on the lesion side of $>95 \%$ depleted animals.

Finally, it is important to note that, although there was a $98 \%$ depletion in extracellular DOPAC and a $96 \%$ depletion in HVA ( $>95 \%$ rats), and no reduction in extracellular DA, there was still more extracellular DOPAC and HVA than DA. That is, on the lesion side of $>95 \%$ rats there were more $\mathrm{pg} / \mu \mathrm{l}$ of DOPAC and HVA than DA (see Fig. 6B,D,F).

\section{Amphetamine-stimulated $D A$ release}

Fig. 7 illustrates the ECF concentrations of DA (expressed as a percent of baseline) following amphetamine in 3 rats which had a $<95 \%$ tissue DA depletion and 3 which had a $>95 \%$ depletion. There are 3 points to be made from Fig. 7. (1) In all cases amphetamine caused a large increase in the ECF concentrations of DA on the intact side. (2) In rats with a $<95 \%$ DA depletion amphetamine also produced a large increase in ECF DA on the lesion side. (3) In animals with $>95 \%$ depletion amphetamine resulted in a pronounced and progressive decrement in the ECF concentrations of DA on the lesion side, to nondetectable levels.

\section{Amphetamine-stimulated rotational behavior}

Fig. 8 shows the number of ipsiversive rotations for each of the 6 animals illustrated in Fig. 7. All of the animals turned towards the lesion side after amphetamine, but there was not a strong relationship be-
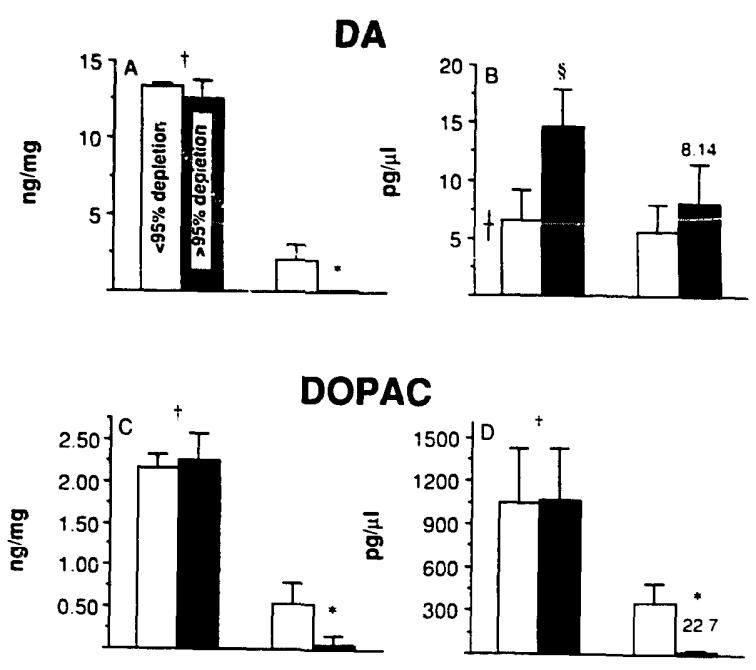

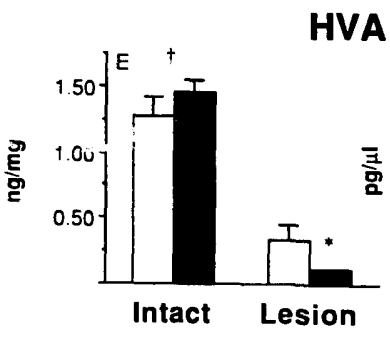

Tissue

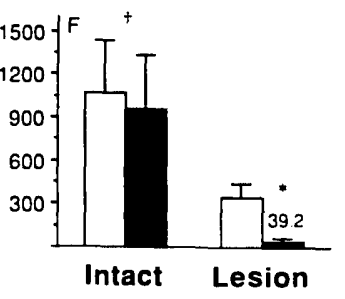

Dialysate
Fig. 6. The mean (+ S.E.M.) concentration of DA, DOPAC and HVA in post-mortem striatal tissue (ng/mg; left column) and striatal dialysate obtained in vivo ( $\mathrm{pg} / \mu \mathrm{l}$; right column) from the intact hemisphere and the hemisphere with a 6OHDA lesion. Open bars represent animals with a $<95 \%$ tissue DA depletion $(n=4$; mean $=84.5 \%)$, and solid bars animals with a $>95 \%$ DA depletion $(n=4$; mean $=99.0 \%)$. In panel $B$ the small horizontal line (far left) represents the mean for a group of 10 rats with no 6-OHDA lesion and the intersecting vertical line \pm S.E.M. The 'sword' $(\dagger)$ indicates that the intact side differs significantly from the lesion side and the asterisk $\left({ }^{*}\right)$ indicates that on the lesion side the $>95 \%$ depletion group differs significantly from the $<95 \%$ depletion group (2way analyses of variance). Note the absence of either a sword or asterisk in panel $\mathrm{B}$. The numbers above the solid bars on the far right show the average concentration of DA, DOPAC, and HVA (respectively) in dialysate $(\mathrm{pg} / \mu \mathrm{l})$ from the lesion side of $>95 \%$ depleted animals. Note that the extracellular concentrations of DOPAC and HVA are greater than DA, despite the massive depletion of DOPAC and HVA on that side. In panel $\mathrm{B}, \S$ indicates that the concentration of DA in dialysate on the intact side of $>95 \%$ depleted rats is significantly greater than: (1) on the lesion side of $>95 \%$ depleted rats (paired $t$-test, $P=$ 0.012 ; (2) on the intact side of $<95 \%$ depleted rats, if rat numbers 1 and 5 are included $(P=0.039)$; and $(3)$ in an independent group of neurologically intact (no lesion) rats $(P=0.003)$. See the text for details. 


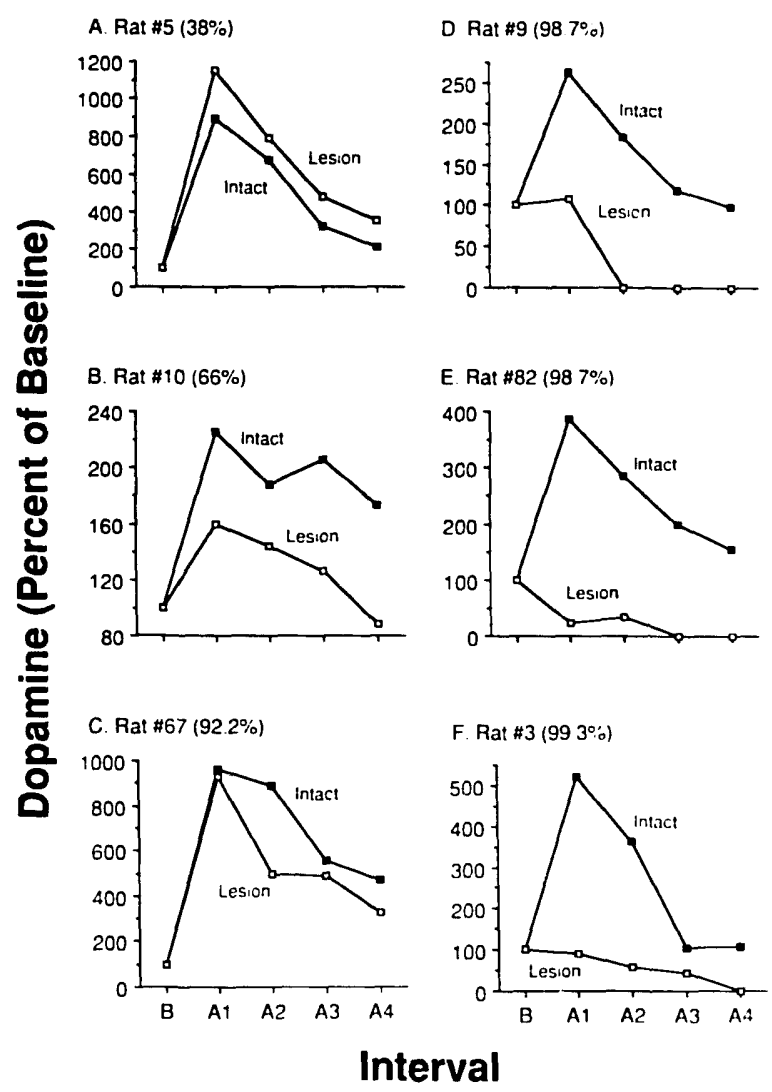

Fig. 7. Extracellular DA concentrations on the intact side and the side with a 6-OHDA lesion (expressed as a percent of the respective baseline values) following $1.5 \mathrm{mg} / \mathrm{kg}$ of D-amphetamine, in 3 rats with a $<95 \%$ DA depletion (left column) and 3 rats with a $>95 \%$ DA depletion (right column). Individual animal numbers and the percent striatal tissue DA depletion for each animal (in parentheses) is given in the upper left portion of each graph. On the horizontal axis B indicates baseline and A1-A4 indicate the 4 successive 30 min samples after amphetamine administration. Symbols that are located directly on the horizontal axis indicate non-detectable values. Note that in animals with a $<95 \%$ depletion amphetamine increased the extracellular concentrations of DA on both the intact and lesion sides. In animals with a $>95 \%$ depletion amphetamine increased the extracellular concentrations of DA only on the intact side, and on the lesion side resulted in a progressive decline in extracellular DA (to non-detectable levels).

tween the vigor of rotation and the magnitude of the asymmetry in DA release (compare Figs. 7 and 8). Rat 5 appears somewhat anomalous because the lesion side released slightly more DA than the intact side, but it turned ipsilateral to the lesion. However, rat 5 made fewer net rotations than any other animal because it frequently switched direction. This is apparent during the first $10 \mathrm{~min}$ interval when rat 5 ac- tually made more contraversive than ipsiversive turns. Furthermore, rat 5 was retested the next day and given $3.0 \mathrm{mg} / \mathrm{kg}$ of amphetamine. During this second test session rat 5 showed more vigorous ipsiversive rotation and the ECF concentrations of DA were at least $20 \%$ higher on the intact side than on the lesion side at all points in time after amphetamine.

\section{DISCUSSION}

One of the most interesting findings in the present study was that during the resting statc lesion size (tissue DA depletion) did not predict DA concentrations in the ECF. Even after a $>95 \%$ reduction in striatal tissue DA content the ECF concentration of DA remained relatively normal. An initial analysis in which the lesion side was expressed as a percent of the intact side suggested that there was a moderate $(34.8 \%)$ reduction in ECF DA on the lesion side, although this was significantly less than the reduction in tissue DA (91.6\%). But further analyses showed that the apparent reduction in ECF DA on the lesion side was not due to a decrease in ECF DA on the lesion side, but actually to an increase in the ECF concentrations of DA on the intact side. This latter interpretation is supported by the following observations. (1) In rats with $<95 \%$ DA depletion (mean = $84.5 \%$ ) ECF DA concentrations were the same on

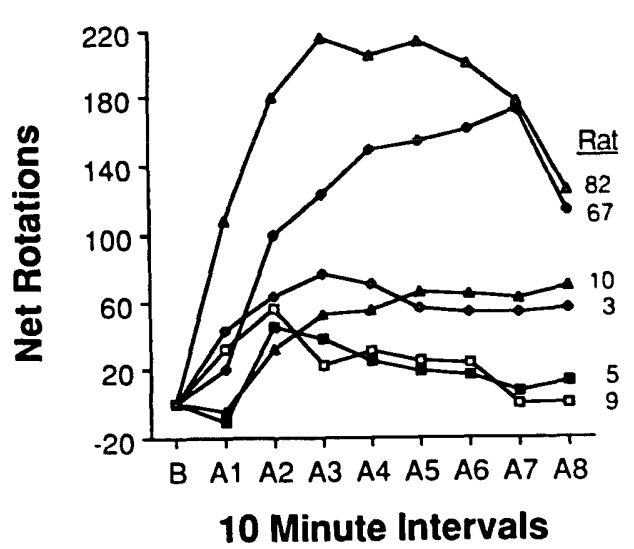

Fig. 8. Net rotations for the 6 individual animals illustrated in Fig. 7. following $1.5 \mathrm{mg} / \mathrm{kg}$ of amphetamine. On the horizontal axis $\mathrm{B}$ indicates baseline and $\mathrm{Al}-\mathrm{A} 8$ indicate 8 successive 15 min intervals following amphetamine. Positive values indicate ipsiversive rotations and negative values contraversive rotations. 
the intact and lesion sides. (2) In rats with $>95 \%$ DA depletion (mean $=99.0 \%$ ) ECF DA concentrations on the lesion side were lower than on the intact side, but the same as on either side of rats with a $<95 \%$ DA depletion. (3) Striatal ECF concentrations of DA on the intact side of $>95 \%$ depleted rats were significantly higher than in an independent group of rats without a lesion.

The observation that a unilateral lesion of substantia nigra elevates the ECF concentrations of DA in the contralateral striatum is not novel, and is supported by behavioral, neurochemical and electrophysiological studies. For example, Zetterström et al. ${ }^{75}$ reported that rats with a unilateral 6-OHDA lesion and a $>95 \%$ DA depletion (as indicated by 2 peak rotation after $0.05 \mathrm{mg} / \mathrm{kg}$ of apomorphine) have significantly elevated basal levels of ECF DA in striatal dialysate obtained contralateral to the lesion, relative to no lesion controls. Similarly, Becker et al. ${ }^{5}$ found that after haloperidol DA metabolite concentrations are elevated in the lateral ventricle (CSF) contralateral to a unilateral 6-OHDA lesion more than in control animals. Furthermore, the spontaneous firing rate of striatal neurons located contrateral to a lesion of the mesostriatal system is decreased $^{25,32}$ long after unit activity has returned to normal in the ipsilateral striatum ${ }^{45,56}$. This observation is consistent with enhanced ECF DA on the side contralateral to a lesion because DA typically inhibits striatal unit activity ${ }^{8,39,45}$. Finally, behavioral studies suggest that the increase in striatal ECF DA contralateral to a mesostriatal lesion may cause a small downregulation of DA receptors on that side, as indicated by a reduced sensitivity to locally applied $\mathrm{DA}^{16}$. Taken together these studies generally support the concept of reciprocal regulation of the two mesostriatal DA systems, and the observation that a unilateral nigral lesion increases DA release in the contralateral striatum ${ }^{44}$. They also establish that manipulation of one striatum influences activity in the other striatum, and therefore, it is not appropriate to use one striatum as a control following unilateral manipulations.

After recovery from a 6-OHDA lesion it is thought that the concentration of DA in striatal tissue provides an accurate index of the number of DA terminals remaining in striatum ${ }^{46,51,78}$. The results suggest, therefore, that following recovery from a unilateral
6-OHDA lesion only one percent of the normal DA input to striatum is required to maintain normal concentrations of DA in the ECF. The ability of the mesostriatal DA system to compensate for such a massive insult is probably due to a couple of factors. One, the spontaneous discharge rate of mesostriatal neurons is normally very low ${ }^{24,26}$, suggesting that the spontaneous rate of DA efflux from individual cells is also low. In addition, many mesostriatal DA neurons are frequently quiescent ${ }^{12,40}$. Therefore, even under normal conditions only a relatively small number of cells may need to be active at low rates to maintain normal striatal ECF DA concentrations, and normal function. Perhaps individual mesostriatal DA neurons 'time share' in a manner analogous to the motor neurons in a motor pool. Second, after a lesion a number of different compensatory neuronal processes probably interact synergistically to upregulate the remaining DA neurons. It is well established that after partial damage the remaining DA cells greatly increase their rate of DA synthesis ${ }^{2,3,28,29,78}$. It is thought that this is a 2-stage process, first involving a change in the affinity of tyrosine hydroxylase for its cofactor, and later an increase in the amount of tyrosine hydroxylase ${ }^{1,79}$. Because DA reuptake sites on DA terminals are destroyed by 6-OHDA there is also a reduction in DA reuptake, and therefore, DA is presumably not removed from the ECF as rapidly after a lesion ${ }^{61,78,79}$. With long-term recovery an additional factor may come into play, which involves the sprouting or regrowth of new terminals. This is suggested by histochemical studies and by an increase in striatal tyrosine hydroxylase and DA concentrations between a few weeks and 2-4 months after a 6OHDA lesion ${ }^{18,46}$. Lastly, there is an increase in the fractional release of DA during electrical stimulation of DA depleted striatal tissue in vitro ${ }^{61}$. Of course, this is consistent with the many reports of an increase in the ratio of DA metabolites to DA following DA depletion (e.g. refs. 7, 29, 31, 58, 78).

There was also a very large increase in the fractional release of DA in vivo in the present study. During the resting state the ECF concentrations of DA on the intact side of $>95 \%$ depleted animals were $0.118 \%$ of the total available DA, but on the lesion side represented $6.33 \%$ of total DA. This is a 53 -fold increase in the proportion of DA located in the extracellular fluid, and presumably available at synapses. 
The normalization of ECF DA is probibly due to this huge increase in DA release from the remaining terminals, and to a lesser extent, to decreased reuptake $^{61}$, but further studies will be required to determine the relative contribution of increased release vs decreased reuptake. It is also important to note that all the animals in the present study had a partial lesion, i.e. there were detectable levels of DA on the lesion side in all animals. Presumably total destruction of striatal DA terminals would result in a complete loss of ECF DA, and this is probably why DA was not detected in dialysate obtained from the lesion side by Zetterström et al. ${ }^{75}$. There is also no recovery of behavioral function after total DA depletion bilaterally ${ }^{35,62}$.

The present study shows for the first time that following recovery from a partial unilateral 6-OHDA lesion of the substantia nigra the remaining DA terminals are not only capable of maintaining relatively high ECF concentrations of DA, but of actually maintaining normal ECF DA concentrations. That the in vivo rate of DA efflux reported here is indeed normal is supported by comparison with previous microdialysis studies. For example, the following basal rates of DA efflux have been reported for striatum (uncorrected for recovery and all expressed as $\mathrm{fmol} /$ min): 7.1 (Wood et al. ${ }^{74}$ ); 7.5 (Hernandez et al..$^{30}$ ); 9.0 (Sharp et al. ${ }^{59}$ ); 9.5 (Zetterström et al. ${ }^{75}$ ); 14.5 (Ungerstedt $^{68}$ ); 17.0 (Westerink and Tuinte ${ }^{71}$ ). In comparison, the basal rate of DA efflux in the present study averaged across all determinations (lesion and intact sides) was $15.3 \mathrm{fmol} / \mathrm{min}$, and for neurologically intact rats was $11.7 \mathrm{fmol} / \mathrm{min}$ (uncorrected for recovery). It is presumably this extraordinary ability of only a small fraction of the DA terminals to maintain normal ECF DA concentrations that is responsible for sparing of function after up to 80-90\% of the DA terminals are destroyed, and in conjunction with receptor supersensitivity, for the recovery of function seen after over $90 \%$ of the DA terminals are destroyed.

Although there is considerable recovery of behavioral function after a partial 6-OHDA lesion, recovery is incomplete, because behavioral deficits may reappear if the system is 'challenged', for example, by exposure to stress ${ }^{60}$. The effects of amphetamine on DA release reported here may help explain why deficits are reinstated by a challenge. In animals with a <95\% DA depletion amphetamine caused an increase in the ECF concentrations of DA on both sides, but less from the lesion side than the intact side. In animals with a $>95 \%$ DA depletion amphetamine caused a large increase in ECF DA on the intact side, but not on the lesion side. In fact, in these latter animals amphetamine caused a progressive decline in ECF DA concentrations to non-detectable levels. These results suggest that although the compensatory changes are sufficient to maintain normal ECF DA concentrations during the resting state they are not necessarily sufficient in demanding situations requiring increased DA release, such as when animals are exposed to stress ${ }^{4.52}$. If the lesion is $<95 \%$ and the demand is not great the remaining terminals may be able to increase DA release well above basal levels (also see ref. 28). If the demand is great or the lesion is large, however, a challenge may deplete the remaining DA stores leading to a reinstatement of symptoms.

In contrast to the disassociation between lesion size and ECF DA there was a very good relationship between lesion size and the ECF concentrations of DOPAC and HVA. The large reduction in the ECF concentrations of DOPAC and HVA was presumably due to the degeneration of DA terminals following the 6-OHDA lesion. Nevertheless, the amount of DOPAC and HVA remaining in the ECF on the lesion side was sufficient to account for all DA metabolism, i.e., even after a >95\% DA depletion there was 3-5 times more DOPAC and HVA (respectively) than DA. These findings provide strong support for the argument that most of the DOPAC found in tissue is locaied intraneuronally and is formed independent of DA release ${ }^{13,70,74}$. Furthermore, the observation that neither post-mortem tissue concentrations of DOPAC and HVA nor ECF concentrations of these DA metabolites were related to the ECF concentrations of DA suggests that DOPAC and HVA are poor indicators of the amount of DA available at the synapse.

In summary, it was found that after recovery from a partial unilateral 6-OHDA lesion the remaining DA terminais are able to maintain normal concentrations of DA in striatal ECF during the resting state. This is presumably due to a number of changes in the damaged striatum, including an increase in DA synthesis and release from the remaining terminals, a 
decrease in DA reuptake, and perhaps the sprouting of new terminals. It will be interesting to determine if the mesostriatal system can also normalize ECF DA concentrations to the extent described here if there is bilateral damage. It is possible that crossed or bifurcating mesostriatal DA projections $\mathrm{s}^{20.48,49}$ contribute to the normalization of ECF DA following unilateral dam?ge, and therefore after bilateral damage the compensatory response may be more modest. Enhanced activity in bifurcating DA neurons could also contribute to the elevation in ECF DA seen contralateral to a lesion. Even after a unilateral lesion the ability of the remaining terminais to compensate is limited, however, because at least after very large lesions $(>95 \%)$ the remaining terminals cannot further increase DA release in response to increased demand. This may help explain why behavioral deficits can be reinstated by stimuli that increase DA release (e.g. stressors, amphetamine), or decrease DA activity (e.g. antidopaminergic drugs). It is nevertheless encouraging that such a small complement of DA terminals can maintain normal ECF DA concentrations and relatively normal function. This suggests that in the case of degenerative disorders, such as Parkin-

\section{REFERENCES}

1 Acheson, A.L. and Zigmond, M.J., Short and long term changes in tyrosine hydroxylase activity in rat brain after subtotal destruction of central noradrenergic neurons, $J$. Neurosci., 1 (1981) 493-504.

2 Agid, Y., Javoy, F. and Glowinski, J., Hyperactivity of remaining dopaminergic neurones after partial destruction of the nigro-striatal dopaminergic system in the rat, Nature (New Biol.), 245 (1973) 150-151.

3 Altar, C.A., Marien, M.R. and Marshall, J.F., Time course of adaptations in dopamine biosynthesis, metabolism, and release following nigrostriatal lesions: implications for behavioral recovery from brain injury, J. Neurochem., 48 (1987) 390-399.

4 Antelman, S.M. and Chiodo, L.A., Amphetamine as a stressor. In I. Creese (Ed.), Stimulants: Neurochemical, Behavioral, and Clinical Perspectives, Raven, New York, 1983, pp. 269-299.

5 Becker, J.B., Adams, F.A. and Robinson, T.E., Intraventricular microdialysis: a new method for determining monoamine metabolite concentrations in the cerebrospinal fluid of freely moving rats, J. Neurosci. Meth., in press.

6 Becker, J.B., Castañeda, E., Robinson, T.E. and Beer, M.E., A simple in vitro technique to measure the release of endogenous dopamine and dihydroxyphenylacetic acid from striatal tissue using high performance liquid chromatography with electrochemical detection, J. Neurosci. son's disease, function may be maintained if methods can be devised to protect even a small fraction of the dopaminergic input to striatum. It also provides hope that replacement of even a small fraction of the normal DA in striatum, for example, by transplantation of adrenal or nigral tissue, will provide effective relief from the symptoms of DA depletion ${ }^{19,23,34}$.

\section{ACKNOWLEDGEMENTS}

This research was conducted while Dr. Whishaw was a Visiting Professor at the University of Michigan, and was on leave from the Department of Psychology, University of Lethbridge, Lethbridge, Alberta, Canada (TIK 3M4), which is his present address. The development of the dialysis method and this research was supported by grants to T.E.R. from the Rackham School of Graduate Studies (The University of Michigan), the Scottish Rite Schizophrenia Research Program and the United States Public Health Service (NIH Grant NS00844). We thank Merrell-Dow Pharmaceuticals for the gift of the desipramine and Dr. J.B. Becker for her comments and assistance.

Methods, 11 (1984) 19-28.

7 Bernheimer, H., Birkmayer, W., Hornykiewicz, O., Jellinger, K. and Seitelberger, F., Brain dopamine and the syndromes of Parkinson and Huntington - clinical, morphological and neurochemical correlations, J. Neurol. Sci., 20 (1973) 415-455.

8 Bloom, F.E., Costa, E. and Salmoiraghi, G.C., Anesthesia and the responsiveness of individual neurons of the caudate nucleus of the cat to acetylcholine, norepinephrine and dopamine administered by microelectrophoresis, J. Pharmacol. Exp. Ther., 150 (1965) 244-252.

9 Bracha, H.S., Shults, C., Glick, S.D. and Kleinman, J.E., Spontaneous asymmetric circling behavior in hemi-parkinsonism: a human equivalent of the lesioned-circling rodent behavior, Life Sci., 40 (1987) 1127-1130.

10 Breese, G.R. and Traylor, T.D., Depletion of brain noradrenaline and dopamine by 6-hydroxydopamine, Br. J. Pharmacol., 42 (1971) 88-99.

11 Castañeda, E., Robinson, T.E. and Becker, J.B., Involvement of nigrostriatal dopamine neurons in the contraversive rotational behavior evoked by electrical stimulation of the lateral hypothalamus, Brain Research, 327 (1985) 143-151.

12 Chiodo, L.A. and Bunney, B.S., Effects of dopamine antagonists on midbrain dopamine cell activity. In E. Usdin, A. Carlsson, A. Dahlstrom and J. Engel (Eds.), Catecholamines, Part B: Neuropharmacology and Central Nervous System, Liss, New York, 1984, pp. 369-391. 
13 Commissiong, J.W., Monoamine metabolites: their relationship and lack of relationship to monoaminergic neuronal activity, Biochem. Pharmacol., 34 (1985) 1127-1131.

14 Cooper, B.R., Breese, G.R., Howard, J.L. and Grant, L.D., Enhanced behavioral depressant effects of reserpine and alpha-methyl-tyrosine after 6-hydroxydopamine treatment, Psychopharmacology, 27 (1972) 99-110.

15 Cooper, P.H.. Novin, D. and Butcher. L.L.. Intracerebral 6-hydroxydopamine produces extensive damage to the brod brain tarricr in rats. Neurosci. Lett., 30 (1982) 13-18.

16 Costall, B., Kelly, M.E. and Naylor, R.J., Does contralateral circling involve action of drugs on hyposensitive striatal dopamine receptors in the hemisphere contralateral to denervation?, Neuropharmacology, 22 (1983) 295-302.

17 Creese, I., Burt, D.R. and Snyder, S.H., Dopamine receptor binding enhancement accompanies lesion-induced behavioral sensitivity. Science, 197 (1977) 596-598.

18 Dravid, A., Jaton, A.L., Enz, A. and Frei. P., Spontaneous recovery from motor asymmetry in adult rats with 6hydroxydopamine-induced partial lesions of the substantia nigra, Brain Research, 311 (1984) 361-365.

19 Dunnett, S.B., Björklund, A. and Stenevi. U., Transplantinduced recovery from brain lesions: a review of the nigrostriatal model. In R.B. Wallace and G.D. Das (Eds.), Neural Tissue Transplantation Research, Springer, New York, 1983, pp. 191-216.

20 Fass, B. and Butcher, L.L.. Evidence for a crossed nigrostriatal pathway in rats, Neurosci. Lett., 22 (1981) 109-113.

21 Feltz, P. and De Champlain, J.. Enhanced sensitivity of caudate neurones to microiontophoretic injections of dopamine in 6-hydroxydopamine treated cats, Brain Research, 43 (1972) 601-605.

22 Fibiger, H.C., Zis, A.P. and McGeer, E.G., Feeding and drinking deficits after 6-hydroxydopamine administration in the rat: similarities to the lateral hypothalamic syndrome, Brain Research, 55 (1973) 135-148.

23 Freed, W.J., Hoffer, B.J., Olson, L. and Wyatt, R.J.. Transplantation of catecholamine-containing tissues to restore the functional capacity of the damaged nigrostriatal system. In J.R. Sladek and D.M. Gash (Eds.), Neural Transplants, Plenum, New York, 1984, pp. 373-406.

24 Freeman, A.S., Meltzer, L.T. and Bunney, B.S., Firing properties of substantia nigra dopaminergic neurons in freely moving rats, Life Sci., 36 (1985) 1983-1994.

25 Garcia-Rill, E., Hull, C.D., Cherubini, E., Levine, M.S. and Buchwald, N.A., The spontaneous firing patterns of forebrain neurons. V. Time course of changes in caudate unit activity following dopamine-depleting lesions, Brain Research, 190 (1980) 415-424.

26 Grace, A.A. and Bunney. B.S., Nigral dopamine neurons: intracellular recording and identification with L-DOPA injection and histofluorescence, Science, 210 (1980) 654-656.

27 Heffner. T.G.. Hartman. J.A. and Seiden. L.S., A rapid method for the regional dissection of the rat brain, Pharmacol. Biochem. Behav.. 13 (1980) 453-456.

28 Hefti, F., Enz, A. and Melamed. E., Partial lesions of the nigrostriatal pathway in the rat-acceleration of transmitter synthesis and release of surviving dopaminergic neurones by drugs, Neuropharmacology, 24 (1985) 19-23.

29 Hefti, F., Melamed, E. and Wurtman, R.J., Partial lesions of the dopaminergic nigrostriatal system in rat brain: biochemical characterization, Brain Research, 195 (1980) 123-137.

30 Hernandez, L., Stanley, B.G. and Hoebel, B.G.. A small, removable microdialysis probe, Life Sci, 39 (1986)
2629-2637.

31 Hornykiewicz, O., Dopamine and extrapyramidal motor function and dysfunction. In Research Publications of the Association for Research in Nervous and Mental Disease, Vol. 50, Williams and Wilkins, Baltimore, 1972, pp. 390-415.

32 Hull, C.D., Levine. M.S., Buchwald, N.A., Heller, A. and Browning. R.A., The spontaneous firing pattern of forebrain neurons. I. The effects of dopamine and non-dopamine depleting lesions on caudate unit firing patterns, Brain Research, 73 (1974) 241-262.

33 Kelley, E. and Nahorski, S.R., Endogenous dopamine functionally activates D-1 and D-2 receptors in striatum. $J$. Neurochem., 49 (1987) 115-120.

34 Madrazo, I.. Drucker-Colín, R.. Díaz, V.. Martínez-Mata. J., Torres. C. and Becerril. J.. Open microsurgical autograft of adrenal medulla to the right caudate nucleus in two patients with intractable Parkinson's disease. N. Eng. J. Med., 316 (1987) 831-834.

35 Marshall. J.F.. Somatosensory inattention after dopaminedepleting intracerebral 6-OHDA injections: spontaneous recovery and pharmacological control, Brain Research, 177 (1979) 311-324.

36 Marshall, J.F., Brain function: neural adaptations and recovery from injury, Annu. Rev. Psychol., 35 (1984) 277-308.

37 Marshall. J.F.. Richardson. J.S. and Teitelbaum, P., Nigrostriatal bundle damage and the lateral hypothalamic syndrome, J. Comp. Physiol. Psychol., 87 (1974) 808-830.

38 Martin, J.P. . The Basal Ganglia and Posture, Pitman, London, 1967.

39 McLennan. H. and York. D.H., The action of dopamine on neurons of the caudate nucleus. J. Physiol. (Lond.). 189 (1967) 393-402.

40 Miller. J.D.. Manjit. K.S. and German. D.C.. Mesencephalic dopaminergic unit activity in the behaviorally conditioned rat, Life Sci., 29 (1981) 1255-1263.

41 Mintz. M. and Myslobodsky. M.S.. Two types of hemisphere imbalance in Hemi-Parkinsonism coded by brain electrical activity and electrodermal activity. In M.S. Myslobodsky (Ed.). Hemisyndromes: Psychobiology, Neurology, Psychiatry, Academic, New York. 1983. pp. 213-238.

42 Mishra, R.K.. Gardner, E.L., Katzman. R. and Makman, M.H., Enhancement of dopamine-stimulated adenylate cyclase activity in rat caudate after lesions in the substantia nigra: evidence for denervation supersensitivity, Proc. Natl. Acad. Sci. U.S.A., 71 (1974) 3883-3887.

43 Neve. K.A.. Kozlowski, M.R. and Marshall. J.F., Plasticity of neostriatal dopamine receptors after nigrostriatal injury: relationship to recovery of sensorimotor functions and behavioral supersensitıvity, Brain Research, 244 (1982) $33-4$ '.

44 Nieoullon. A.. Cheramy. A. and Glowinski. J.. Interdependence of the nigrostriatal dopaminergic systems on the two sides of the brain in the cat. Science, $198(1977)+16-418$.

45 Nisenbaum, E.S.. Stricker. E.M.. Zigmond. M.J. and Berger, T.W.. Long-term effects of dopamine-depleting brain lesions on spontaneous activity of type II striatal neurons: relation to behavioral recovery. Brain Research, 398 (1986) 221-230.

46 Onn, S., Berger, T.W. Stricker, E.M. and Zigmond. M.J.. Effects of intraventricular 6-hydroxydopamine on the dopaminergic innervation of striatum: histochemical and neurochemical analysis, Brain Research, 376 (1986) 8-19.

47 Paxinos. G. and Watson, C.. The Rat Brain in Stereotaxic Coordinates, 2nd edn., Academic. New York. 1986. 
48 Pritzel, M., Huston, J.P. and Sarter, M., Behavioral and neuronal reorganization after unilateral substantia nigra lesions: evidence for increased interhemispheric nigrostriatal projections, Neuroscience, 9 (1983) 879-888.

49 Pritzel, M., Sarter, M., Morgan, S. and Huston, J.P., Interhemispheric nigrostriatal projections in the rat: bifurcating nigral projections and loci of crossing in the diencephalon. Brain Res. Bull., 10 (1983) 385-390.

50 Pycock, C.J., Turning behavior in animals, Neuroscience, 5 (1980) 461-514.

51 Ranje, C. and Ungerstedt. U., High correlations between number of dopamine cells, dopamine levels and motor nerformance, Brain Research, 134 (1977) 83-93.

52 Robinson, T.E., Becker, J.B., Young, E.A., Akil, H. and Castañeda, E., The effects of footshock stress on regional brain dopamine metabolism and pituitary $\beta$-endorphin release in rats previously sensitized to amphetamine, Neuropharmacology, 26 (1987) 679-691.

53 Schallert. T.. Whishaw, I.Q.. Pamirez. V.D. and Teitelbaum. P.. Compulsive, abnormal walking caused by anticholinergics in akinetic, 6-hydroxydopamine-treated rats. Science, 199 (1978) 1461-1463.

54 Schallert, T.. Whishaw, I.Q.. Ramirez. V.D. and Teitelbaum. P.. The postures of catecholamine depletion catalepsy: their possible adaptive value in thermoregulation, Physiol. Behav.. 21 (1978) 817-820.

55 Schultz, W., Depletion of dopamine in the striatum as an experimental model of Parkinsonism: direct effects and adaptive mechanisms, Prog. Neurobiol., 18 (1982) 121-166.

56 Schultz, W. and Ungerstedt, U., Short-term increase and long-term reversion of striatal activity after degeneration of the nigrostriatal dopamine system, Exp. Brain Res., 33 (1978) 159-171.

57 Schwab, R.S. and Zieper, I., Effects of mood, motivation, stress and alertness on the performance in Parkinson's disease, Psychiatr. Neurol., 150 (1965) 345-357.

58 Sharman, D.F., Poirier, L.J., Murphy, G.F. and Sourkes, T.L., Homovanillic acid and dihydroxyphenylacetic acid in the striatum of monkeys with brain lesions, Can. J. Physiol. Pharmacol., 45 (1967) 57-62.

59 Sharp, T., Zetterström, T., Ljungberg, T. and Ungerstedt, U., A direct comparison of amphetamine-induced behaviours and regional brain dopamine release in the rat using intracerebral dialysis, Brain Research, 401 (1987) 322-330.

60 Snyder, A.M., Stricker, E.M. and Zigmond, M.J., Stressinduced neurological impairments in an animal model of parkinsonism, Ann. Neurol., 18 (1985) 544-551.

61 Stachowiak, M.K., Keller, R.W., Stricker, E.M. and Zigmond, M.J., Increased dopamine efflux from striatal slices during development and after nigrostriatal bundle damage, J. Neurosci., 7 (1987) 1648-1654.

62 Stricker, E.M. and Zigmond, M.J., Recovery of function after damage to central catecholamine-containing neurons: a neurochemical model for the lateral hypothalamic syndrome. In J.M. Sprague and A. Epstein (Eds.), Progress in Psychobiology and Physiological Psychology, Vol. 6, Academic, New York, 1976, pp. 121-187.

63 Stricker, E.M. and Zigmond, M.J., Effects on homeostasis of intraventricular injections of 6-hydroxydopamine in rats, J. Comp. Physiol. Psychol., 86 (1974) 973-994.

64 Stricker, E.M. and Zigmond, M.J., Brain monoamines, homeosiasis, and adaptive behavior. In Handbook of Physiology, Intrinsic Regulatory Systems of the Brain, Vol. IV, American Physiology Society, B?thesda, MD, 1986, pp.
677-696.

65 Thornburg, J.E. and Moore, K.E., Supersensitivity to dopamine agonists following unilateral, 6-hydroxydopamine-induced striatal lesions in mice, J. Pharmacol. Exp. Ther., 192 (1975) 42-49.

66 Ungerstedt, U.. Adipsia and aphagia after 6-hydroxydopamine induced degeneration of the nigrostriatal dopamine system, Acta Physiol. Scand., 82 (1971) 96-122.

67 Ungerstedt, U.. Postsynaptic supersensitivity after 6-hydroxydopamine induced degeneration of the nigrostriatal dopamine system. Acta Physiol. Scand., 82 (1971) 69-92.

68 Ungerstedt, U., Measurement of neurotransmitter release by intracranial dialysis. In C.A. Marsden (Ed.), Measurement of Neurotransmitter Release In Vivo, Wiley, New York, 1984, pp. 81-105.

69 Wages, S.A., Church, W.H. and Justice, J.B., Jr., Sampling considerations for on-line microbore liquid chromatography of brain dialysate, Anal. Chem., 58 (1986) 1649-1656.

70 Westerink, B.H.C., Sequence and significance of dopamine metabolism in the rat brain, Neurochem. Int., 7 (1985) 221-227.

71 Westerink, B.H.C. and Tuinte, M.H.J., Chronic use of intra-cerebral dialysis for the in vivo measurement of 3,4-dihydroxyphenylethylamine and its metabolite 3,4-dihydroxyphenylacetic acid, J. Neurochem., 46 (1986) 181-185.

72 Whishaw, I.Q. and Dunnett, S.B., Dopamine depletion, stimulation or blockade in the rat disrupts spatial navigation and locomotion dependent upon beacon or distal cues, $B e$ hav. Brain Res., 18 (1985) 11-29.

73 Whishaw, I.Q., Robinson, T.E., Schallert, T., De Ryck, M. and Ramirez, V.D., Electrical activity of the hippocampus and neocortex in rats depleted of brain dopamine and norepinephrine: relations to behavior and effects of atropine, Exp. Neurol., 62 (1978) 748-767.

74 Wood, P.L., Kim, H.S. and Marien, M.R., Intracerebral dialysis: direct evidence for the utility of 3-MT measurements as an index of dopamine reluase, Life Sci., 41 (1987) $1-5$.

75 Zetterström, T., Herrera-Marschitz, M. and Ungerstedt, U., Simultaneous measurement of dopamine release and rotational behaviour in 6-hydroxydopamine denervated rats using intracerebral dialysis, Brain Research, 376 (1986) $1-7$.

76 Zigmond, M.J. and Stricker, E.M., Recovery of feeding and drinking by rats after intraventricular 6-hydroxydopamine or lateral hypothalamic lesions, Science, 182 (1973) 717-720.

77 Zigmond, M.J. and Stricker, E.M., Adaptive properties of monoaminergic neurons. In A. Lajtha (Ed.), Handbook of Neurochemistry, Alterations of Metabolites in the Nervous System, Vol. '), Plenum, New York, 1985, pp. 87-102.

78 Zigmond, M.J., Acheson, A.L., Stachowiak, M.K. and Stricker, E.M., Neurochemical compensation after nigrostriatal bundle injury in an animal model of preclinical parkinsonism, Arch. Neurol., 41 (1984) 856-861.

79 Zigmond, M.J., Stachowiak, M.K., Berger, T.W. and Sticker, E.M., Neurochemical events underlying continued function despite injury to monoaminergic systems, Exp. Brain Res., (1986) 119-128.

80 Zis, A.P., Fibiger, H.C. and Phillips, A.G., Reversal by LDOPA of impaired learning due to destruction of the dopaminergic nigroneostriatal projection, Science, 185 (1974) 960-962. 